\title{
A DEFinição da FENOMENOLOGIA: Merleau-Ponty leitor de Husserl
}

Cristiano Perius ${ }^{1}$

\begin{abstract}
RESUMO: O trabalho de definir o que é a fenomenologia, desde a Fenomenologia da Percepção, suscitou uma tomada de partido em relação ao pai da fenomenologia. A crítica ao idealismo de Husserl, o papel da ambiguidade, a impossibilidade de redução completa, entre outros grandes temas, personalizam a fenomenologia de Merleau-Ponty em relação ao mestre. O objetivo do ensaio é mostrar como, na descrição do "método" fenomenológico, Merleau-Ponty se afasta dos conceitos fundamentais de Husserl, sem deixar de retornar continuamente a ele.
\end{abstract}

PALAVRAS-CHAVE: Merleau-Ponty. Fenomenologia. Husserl.

O trabalho de definir o que é a fenomenologia, desde o prefácio da Fenomenologia da Percep̧̧ão - em que Merleau-Ponty reabre essa questão "cinquenta anos depois", como ele mesmo diz —, é marcado por uma experiência de mão dupla: de um lado, a convicção de estar diante de uma herança husserliana, de que a interlocução com Husserl não deixa nenhuma dúvida (desde $A$ Estrutura do Comportamento e a Fenomenologia da Percepsão, passando pelos textos intermediários, como O Filósofo e sua Sombra, até o fim da vida, com as Notas de Curso sobre a Origem da Geometria de Husser), significando uma identificação temática que o atravessa de ponta a ponta, e, de outro, uma diferença de projeto, ao mesmo tempo, de que o trabalho de retorno às definições de Husserl, na introdução da Fenomenologia, não é senão o primeiro indício: "O que é a fenomenologia? Pode parecer estranho que se tenha que colocar essa questão meio século depois dos primeiros trabalhos de Husserl. No entanto, ela está longe de ser resolvida" (MERLEAU-PONTY, 1945, p. I). Se acompanharmos esse texto, que é o Prefácio da Fenomenologia, veremos que,

\footnotetext{
${ }^{1}$ Professor da UEM - Universidade Estadual de Maringá. E-mail: cristianoperius@hotmail.com.
} 
curiosamente, foi a indefinição de Husserl que chamou a atenção de MerleauPonty, porque o movimento de retorno e retomada da fenomenologia sobre si mesma não é uma dificuldade de momento - que reclamaria uma solução a tempo - mas de princípio, isto é, a filosofia de Husserl inaugura, assim como o método cartesiano, segundo a expressão de Pierre Thévenaz (1966, p. 34) "[...] mais do que uma metafísica, uma maneira de recolocar em novas bases a filosofia", um campo de problemas ou uma maneira de resolver problemas que traz ao pensamento a questão do surgimento de si mesmo. É porque “[...] a fenomenologia não é acessível senão a um método fenomenológico" (MERLEAU-PONTY, 1945, p. II) que não é uma doutrina, um saber, um conjunto de teses ou de ideias, porém, um projeto incoativo, "[...] laborioso como a obra de Balzac, Proust, Valéry ou Cézanne" (MERLEAU-PONTY, 1945, p. XVI), pois a fenomenologia não é neutra em relação a suas respostas e conceitos, mas subentende a si mesma enquanto possibilidade de pergunta por um campo sobre qual está inclinada e suspendida como questão de fato. Se é laboriosa como a obra do escritor, e condenada a recomeçar indefinidamente em torno de si mesma, não é por conter um mistério qualquer, mas conter a exigência de surpreender o nascimento de si mesma, através de uma interrogação contínua que não ultrapassa o seu objeto, mas se compreende através dele, e assim o exige, toda vez que interrogar o que ela é. Como sublinha Merleau-Ponty, no Prefácio da Fenomenologia da Percepscão (1945, p. XVI):

Seria preciso que a fenomenologia dedique a si mesma a interrogação que endereça a todas as ciências, desdobrando-se infinitamente. Ela será, como diz Husserl, um diálogo ou uma meditação infinita e, na medida em que permanece fiel a sua intenção, não saberá jamais aonde vai. $\mathrm{O}$ inacabamento da fenomenologia e seu estilo incoativo não são signos de um fracasso. Eles eram inevitáveis, porque a fenomenologia tem por tarefa revelar o mistério do mundo e o mistério da razão. Se a fenomenologia foi um movimento antes de ser uma doutrina ou um sistema, não é por acaso, nem impostura. Ela é laboriosa como a obra de Balzac, ou aquela de Proust, Valéry ou Cézanne, - pelo mesmo gênero de atenção e de espanto, pela mesma exigência de consciência, pela mesma vontade de compreender o sentido do mundo e da história em estado nascente.

Ora, a exigência de revelar o mistério do mundo e o mistério da razão não é diferente do que Merleau-Ponty chamou de "[...] refletir sobre um irrefletido", isto é, o movimento de retorno ao mundo natural ou à vida irrefletida, "[...] que é nossa situação inicial, constante e final", "[...] para lhe dar enfim um estatuto 
filosófico" (MERLEAU-PONTY, 1945, p. I). Como aponta Merleau-Ponty (1960, p. 206), em O Filósofo e sua Sombra:

Quando Husserl diz que a redução supera a atitude natural, é para logo acrescentar que essa superação conserva "o mundo inteiro da atitude natural". [...] Há uma preparação da fenomenologia na atitude natural. É a atitude natural, reiterando os seus procedimentos, que passa para a fenomenologia. É ela mesma que se supera na fenomenologia - e portanto não se supera.

O modelo da reflexão não é mais aquele que se deixa conduzir pela clareza das ideias, meio em que a consciência é absoluta, mas questão pelos objetos que não perdem o estatuto de fenômenos irredutíveis, espontâneos e jamais inteiramente dados. Isso significa que a reflexão fenomenológica, em estado de iniciação contínua, não segue mais o modelo da possessão de objetos, mas do contato por imersão ou inerência, que não é um recorte, mas um todo indiviso, do qual também faz parte - como no Drawing Hands, de 1948, de M. C. Escher: a mão que desenha a mão é representada desenhando-se, isto é, impossível separar o desenhado e o desenhante. Porque a filosofia que visa a relatividade do Espírito e da Natureza (pensados juntos, sem dicotomia) deve começar sabendo o que ela é, ou seja, filosofia da gênese, união do "[...] extremo subjetivismo com o extremo objetivismo” (MERLEAU-PONTY, 1945, p. XV).

O retorno à vida irrefletida não significa que devemos abandonar a reflexão para voltar ao caos das sensações, mas que a reflexão encontra, através dos atos da consciência constituinte, apenas a verdade de si mesma (segundo o modelo seminal das Meditações de Descartes, onde o pensamento funda a verdade de sua natureza partindo pura e simplesmente de si mesmo) $)^{2}$. Ao criticar o cogito cartesiano, Merleau-Ponty não está abandonando a reflexão, porém, sustentando que ela é unilateral e absoluta, se não nascer das coisas, isto é, de suas relações, pois a "razão" fenomenológica não é autônoma (no sentido que a modernidade deu a esse termo, com o projeto de fundação do sujeito autônomo), mas teleológica, presumida e incompleta — como se predestinada a acontecer mais de fato do que de direito. Ora, era mais ou menos por isso que Merleau-Ponty recomendava uma leitura existencial, não idealista, da redução fenomenológica de Husserl. MerleauPonty recusa a consciência constituinte em nome de um prejuízo do pensamento reflexionante: o esquecimento de um pensamento naturado em favor de um pensamento naturante. Dessa forma, a reflexão é necessária para Merleau-Ponty, porque ela é a unidade da fé perceptiva com a verdade, movimento de retorno da

\footnotetext{
${ }^{2}$ Conforme a famosa estória do Barão de Münchausen: aquele que desce as profundezas do oceano, por não saber nadar, basta, para que suba à superfície, puxar-se pelos cabelos...
} 
reflexão sobre as coisas mesmas, para compreender seu próprio sentido, todavia, não pode ser a conversão do campo fenomenal em campo transcendental.

É nessa direção que Luiz Damon caminha, no momento de traçar o projeto da fenomenologia da percepção: "À tentativa de explorar o irracional e integrá-lo a uma razão alargada, tarefa que Merleau-Ponty se consagrou, lhe foi preciso, diante de Husserl, redefinir o campo fenomenal" (MOUTINHO, 2006, p. 97). Segundo Pascal Dupond (2004, p. 113), "[...] a consciência transcendental desconhece a diversidade irredutível das figuras da consciência (consciência mórbida, consciência primitiva, consciência infantil). O cogito cartesiano recusa o real em nome do possível, e por isso nega o sonho, o mito, a alucinação psicótica, como experiências originárias e modos de abertura do mundo", de modo que a reflexão fenomenológica merleau-pontyana não caminha do mundo para a unidade da consciência. (Desde a primeira página do Prefácio: "A fenomenologia é o estudo das essências, mas a fenomenologia é também uma filosofia que recoloca as essências na existência" - que lembram os seguintes versos de Drummond, em "O Relógio do Rosário": "E nada bastal nada é de natureza assim tão castal que não macule ou perca sua essêncial ao contato furioso da existência".) Dessa maneira, o cogito, longe de ser o ato fundamental da consciência, ou do sujeito, presença a mim do meu pensamento, se dá na espessura da existência cuja essência não é um saber, mas "refletir sobre um irrefletido".

O que estamos destacando, neste momento, e que fica apenas em esboço, é uma mudança de vocabulário em relação ao pai da fenomenologia, que já aparece no Prefácio da Fenomenologia. A crítica ao idealismo de Husserl, o papel da ambiguidade, a impossibilidade de redução completa, o quiasma, a carne, o lógos do mundo estético, entre outros grandes temas, personalizam a fenomenologia de Merleau-Ponty em relação ao mestre. Assim, o parentesco e a simpatia intelectual, se apontam para a herança husserliana, criadora do método, de um lado, também o afastam de Husserl, no momento de recolocar a fenomenologia em curso. (Avatar de todo filósofo que lê outro filósofo: modificá-lo, no momento de prestar-lhe homenagem - abrindo-se para o impensado, definido, em O Filósofo e sua Sombra, como o que "pertence bem a ele e leva a outra coisa".)

Marilena Chaú, na introdução ao volume Merleau-Ponty da coleção "Os Pensadores” (1984, p. VIII), marca da seguinte forma o projeto de Merleau-Ponty em relação a Husserl.

Suas primeiras obras estavam nitidamente vinculadas à fenomenologia husserliana, embora procurasse a cada passo minimizar o papel constituinte da consciência e outorgar à relação corpo-sensível / mundo-sensível o poder doador de significados que Husserl atribuíra ao Sujeito Transcendental. A partir de Signos, Merleau-Ponty encaminha-se para a ontologia como região pré- 
reflexiva, selvagem e bruta, de onde emergem as categorias reflexivas. A filosofia - reflexão - deve voltar às origens da própria reflexão e descobrir o seu solo anterior à atividade reflexiva e responsável por ela. Essa região é o "lógos do mundo estético", isto é, do mundo sensível, unidade indivisa do corpo e das coisas, unidade que desconhece a ruptura reflexiva entre sujeito e objeto.

Marilena Chauí parece seguir, na passagem acima, o desenho que Françoise Dastur faz entre os filósofos:

Abandono da posição de sobrevôo deste espectador transcendental que é ainda o fenomenológico para Husserl, e reabilitação ontológica do sensível: tal é o programa da fenomenologia merleau-pontyana, na medida onde implica uma "ontologia do visível", que só é possível porque o visível não tem a positividade de um ser pleno, porque é ambíguo, e porque há uma abertura da fenomenologia sobre o invisível, qualquer coisa como uma "fenomenologia do inaparente", semelhante aquela de que reclamava Heidegger em seus últimos seminários. (DASTUR, 2001, p. 76).

Trata-se de sublinhar o estatuto da reflexão merleau-pontyana à luz da "[...] dupla gênese do mundo e da reflexão, do ser e do ser pensado, e não somente a correlação do pensamento e do ser objeto" (DASTUR, 2001, p. 76). No entanto, essa é a portée (que traduzimos por "alcance", "conquista") do corpo, no primeiro momento, e do sensível, no segundo, e que exigiu, como sabemos, a passagem de um período descritivo dos fenômenos corporais, realizado na Fenomenologia da Percepção, para a ontologia propriamente dita, em $O$ Visivel e o Invisivel. Com a mudança de vocabulário - no lugar de consciência/objeto: visível/invisível —, estamos ainda mais longe da noese e do noema de Husserl, onde a dimensão hylética não será, para Merleau-Ponty, senão uma transposição intelectualista das categorias da percepção (explicitado pelo nó górdio ou o quiasma do sensciente-sensível, já que é preciso ser visto para ver, tocar para ser tocado etc.). Como enfatiza Merleau-Ponty, em O Visivel e o Invisivel (1964, p. 231): “[...] a visão mesma já faz o que a reflexão não compreenderá jamais: que o combate seja algumas vezes sem vencedor e o pensamento doravante sem titular." É a partir desta intraontologia ou endo-ontologia, no interior ou na profundidade do sensível, que será ultrapassada a dualidade da matéria e da forma através da qual Husserl reconstituía a intencionalidade. Outra nota de O Visivel e do Invisivel é clara, nesse movimento de mudança de vocabulário em relação a Husserl: "Trata-se de proceder a redução fenomenológica, isto é, para mim, de desvelar, lenta e progressivamente, o mundo selvagem ou vertical" (MERLEAU-PONTY, 1964, p. 231). 
Ora, o mundo selvagem ou vertical nada mais é, segundo Françoise Dastur (2001, p. 184), do que "[...] um pressentimento constitutivo do processo fenomenológico no que ele tem de mais profundo: a impossibilidade de recuperação do ser no sujeito ativo, pois há uma pré-possessão de uma totalidade que está lá antes de que se saiba como e por quê". A reflexão não mais ignora que é a reconstrução retrospectiva que encontra um mundo mais antigo do que ela, da qual faz parte. Não há apreensão dos dados imediatos da consciência sem pressuposição ou prejuízo em favor do mundo, pois “[...] uma reflexão que ser quer radical não deveria ignorar o ponto cego do espírito” (MERLEAU-PONTY, 1964, p. 55).

Não é outra a conclusão das Notas de Curso (1959-1961). "O que é a filosofia?", pergunta Merleau-Ponty, mais uma vez, ao final da vida²:

A filosofia deve definir-se pela reconquista do Lebenswelt [mundo vivido] através de uma Wissenchaftlichkeit [ciência] de um novo tipo: saber que é nãosaber. [...] A filosofia está em meu Prasenz-Feld [campo de presença] sob a forma de dunkles Wissen [saber obscuro] e não de definição ou de Wortbedeutung [significado das palavras]. [...] Erro de crer que a filosofia são as idéias, ela é um campo com uma interrogação que não sabe o que ela mesma pergunta. (MERLEAU-PONTY, 1996, p. 86).

Se levamos a sério a condição de não-saber e de saber obscuro, contidos no horizonte dessa "filosofia de novo tipo", vemos que a interrogação filosófica só se sustenta verdadeiramente se não for a apreensão direta de um conteúdo sem que algo lhe escape à ordem de encadeamentos lógicos e explícitos, irrevelado à atividade da consciência, mas o processo de retorno a questões que nunca se exauriram, isto é, uma zona de recuo do invisível sobre o visível (que os heideggerianos chamam de recuo do ser, "retrait de l'être", diferença ontológica etc.), como um fundo de silêncio que sobrevive a toda grande fala. Pois é da natureza da reflexão essa condição de fato, mais do que de direito: pertencer a uma experiência de mundo que chega "antes" dela, e ainda assim a exige, quando todo começo efetivo é um segundo momento. Desse modo, a reflexão — considerada pela tradição filosófica, desde Descartes, autoevidente — é conduzida a um grau de transparência máxima para um grau de transparência mínima. Tudo se passa como se a radicalização da reflexão a levasse a valorizar exatamente o que ela ignora e não realiza.

Sublinhemos esse "não", já contido no saber escuro ou no saber de novo tipo (saber que é não saber). "Refletir é desvelar um Boden [solo, terra, chão], um Selsbtverständliches [inteligível por si, inteligivel natural]. Espanto diante da não-

\footnotetext{
3 Final da vida de fato, não de direito, já que o filósofo morre, como se sabe, vítima de embolia cerebral, em 1961.
} 
filosofia" (MERLEAU-PONTY, 1996, p.69). Essa última frase, também das Notas de Curso, abre-se a uma reflexão de novo tipo, como a que ocorre com a poesia, que, se não é filosofia, não é extrafilosófica. Trata-se do curso ministrado no Collège de France, entre 1958 e 1959, onde há um capítulo dedicado à não-filosofia. O título é A filosofia em face dessa não-filosofia, cujo objeto é a literatura, a pintura, a música e a psicanálise, que começa exatamente por Husserl, no capítulo que se chama: Husserl: a filosofia como problema. O que estamos sublinhando, neste momento, e não deve passar despercebido, é que o gesto de recolocar em questão o que é a filosofia, na década de 1960, retorna mais uma vez a Husserl. Mas esse é o movimento de retorno da filosofia sobre si mesma que, como vimos, MerleauPonty já tinha feito antes, desde o Prefácio da Fenomenologia da Percepsãa ${ }^{4}$.

Nas Notas de Curso sobre a Origem da Geometria de Husserl, que foi o último curso ministrado em vida, Merleau-Ponty salienta que "[...] o universo do pensamento, como aquele da percepção, é lacunar e barroco em si mesmo, pois que há uma evidência lateral, entre os atos, e não somente uma evidência progressiva e frontal, e tudo isso porque pensar não é ter, mas não ter"' (1998, p. 30 , grifos do autor).

Pode-se dizer que o conceito de filosofia e o estatuto da reflexão caminham, no projeto fenomenológico de Merleau-Ponty, para a afirmação de seus limites. Contudo, os limites não são mais, como se poderia crer, o fechamento nos conceitos estabelecidos pelo método fenomenológico, mas abertura para a nãofilosofia. De fato, a reflexão só é radical, isto é, séria, se for consciente do que ela perde: a representação ideal, para ganhar com a ambiguidade da existência. Mais ainda, a reflexão só é radical, quer dizer, séria, se retorna ao vivido sabendo que não sabe, a saber: a pressuposição de um mundo, que por sua vez pressupõe uma consciência que já vem tarde. O esquecimento da consciência, e tudo o que ela perde, agora, é positivo, como um gradiente negativo, pois a filosofia e o estatuto da reflexão, em Merleau-Ponty, incorporam o negativo, ou, se quisermos, positivamente, a passividade da consciência. Porém, essa é, para Françoise Dastur, a função do retorno ao Husserl da "fungierende Intentinalität (intencionalidade operante), da intencionalidade sem atos, da unidade antrepredicativa, anônima e oculta entre o mundo e nossa vida, na Krisis e nos Ideen IP", nessa leitura que

\footnotetext{
4 Citemos outra vez, a fim de lembrar o leitor, a passagem que estamos indicando: "O que é a fenomenologia? Pode parecer estranho que se tenha que colocar essa questão meio século depois dos primeiros trabalhos de Husserl. No entanto, ela está longe de ser resolvida" (MERLEAU-PONTY, 1945, p. I).
} 
T. Geraetz (1971, p. 19) chamou de "[...] estratégica e bem seletiva que MerleauPonty procurou fazer de Husserl”.

Talvez possamos dizer, ao contrário de Françoise Dastur e T. Geraetz, ou ao lado deles, para além deles, que essa não foi só uma leitura estratégica e seletiva, mas necessária, para revelar a sua própria filosofia. Merleau-Ponty jamais parou de reler e redescobrir Husserl... Para modificá-lo? Não, para modificar-se!

Podemos agora retornar a uma frase que já lemos, sobre o impensado de Husserl, que Merleau-Ponty (1960, p. 202) define como "[...] ce qui est bel et bien à lui et qui porte sur autre chose" (que pertence bem a ele e, no entanto, abre a outra coisa)... Não é aonde Husserl não foi ou deixou de ir, nas sucessivas tentativas de reeditar a fenomenologia; ao contrário, é o lugar em que, sem ele, Merleau-Ponty não teria ido.

PERIUS, Cristiano. The definition of phenomenology: Merleau-Ponty as reader of Husserl. Trans/Form/Ação, Marília, v. 35, n. 1, p. 137-146, Jan./Abril, 2012.

\begin{abstract}
The task of defining phenomenology, ever since The Phenomenology of Perception, has induced a taking of sides with regard to who the true father of phenomenology is. The critique of Husserl's idealism, the role of ambiguity, the impossibility of complete reduction, among other great themes, personalizes the phenomenology of Merleau-Ponty in relation to that of his master. The object of this article is to show how, in his description of the "phenomenological method", MerleauPonty moves away from the fundamental concepts of Husserl without ceasing to continually return to them.
\end{abstract}

KEYWORDS: Merleau-Ponty; Husserl; phenomenology.

\footnotetext{
${ }^{5}$ É bom frisar que o propósito deste ensaio — já indicado desde o título — "Merleau-Ponty leitor de Husserl" — não está na relação fecunda e privilegiada entre Merleau-Ponty e Husserl, mas nos elementos, unilaterais e sub-reptícios, que constituem uma leitura. Ao considerar o Merleau-Ponty leitor, não se está aludindo a uma relação de dependência, das famosas (e famigeradas) "influências", em que o segundo se submete ao primeiro, como se estivesse diante de uma relação de causa e efeito. Ao tratar de Merleau-Ponty como leitor, está-se falando do genitivo subjetivo do "leitor de", do Husserl de MerleauPonty, caracterizado pela maneira como ele o lê. Ao contrário de um Husserl homogêneo, submetido à tradição fenomenológica tanto alemã (caracterizada, sobretudo, por Heidegger), quanto francesa (Sartre e Merleau-Ponty), sem recortes, sem relevos, sem leituras, estamos diante da atividade de recepção meditativa e infinita, implicada pelo pensamento de um filósofo que vai a outro filósofo e não apenas que vem dele. (Mais ou menos como o Deleuze que vai a Bergson e a Nietzsche não é o Deleuze que sofre "influências de".) Ao pensar o Merleau-Ponty leitor, a questão que se coloca é a seguinte: "leitor... qual leitor?", pois, se estamos nos fazendo entender, o Hegel de Merleau-Ponty não é o da lógica, mas da fenomenologia do Espírito. Portanto, melhor do que "influenciado por" é o "leitor de", para sublinhar a atividade criadora e meditativa dos filósofos que tratam de outros filósofos.
} 


\section{REFERÊNCIAS}

BARBARAS, Renaud. L'être du phénomène: sur l'ontologie de Merleau-Ponty. Paris: Jerome Millon, 2001.

CHAUÍ, Marilena. Vida e obra. In: Merleau-Ponty - Textos escolhidos. São Paulo: Abril Cultural, 1984. (Coleção Os Pensadores)

DASTUR, Françoise. Chair et langage - essais sur Merleau-Ponty. Paris: Encre Marine, 2001.

DUPOND, Pascal. La réflexion charnelle: la question de la subjectivité chez MerleauPonty. Paris: Ousia, 2004.

MERLEAU-PONTY, Maurice. Le visible et l'invisible. Paris: Gall Notes de cours (1959-1961). Paris: Gallimard, 1996.

. Notes de cours sur l'origine de la géométrie de Husserl. Paris: PUF, 1998.

Phénomenologie de la perception. Paris: Gallimard, 1945.

Signes. Paris: Gallimard, 1960.

MOUTINHO, Luis Damon Santos. O projeto da fenomenologia da percepção. In: PINTO, Débora Morato; MARQUES, Rodrigo Vieira (Org.). A fenomenologia da experiência - horizontes filosóficos da obra de Merleau-Ponty. Goiânia: Editora da UFG, 2006.

THÉVENAZ, Pierre. De Husserl à Merleau-Ponty. In: Qu'est-ce que 1a phénoménologie? Neuchâtel: Editions de la Baconnière, 1966.

Recebido em: 04.08.2011

Aprovado em: 18.11.2011 
PERIUS, C. 